\title{
BUDAYA KERJA, KEDISIPLINAN DAN INSENTIF TERHADAP KINERJA KARYAWAN UNIVERSITAS TUNAS PEMBANGUNAN (UTP) SURAKARTA
}

\author{
Wahyuningsih, Sri Hartono, Djumali \\ Fakultas Ekonomi Universitas Islam Batik Surakarta \\ Email:niningwb@gmail.com
}

\begin{abstract}
The purpose of this study is to analyze the effect of work culture, discipline and incentives on the performance of employees of the Universitas Tunas Pembangunan (UTP) Surakarta. The population in this study was 63 employees Universitas Tunas Pembangunan (UTP) Surakarta. The sampling technique is a census sample by taking a sample with a total of 63 respondents. Data collection uses a Likert scale questionnaire to measure respondents answers to identify the relationship between work culture, discipline and incentives for employee performance. The results show that work culture, discipline and incentives have a simultaneous and significant effect on employee performance, work culture has a significant effect on employee performance, discipline has a significant effect on employee performance, and incentives have an effect on employeeperformance.
\end{abstract}

Keywords: work culture, discipline, incentive, employee performance

\section{PENDAHULUAN}

Dalam menghadapi persaingan di era globalisasi dituntut untuk bekerja lebih efisien dan efektif. Persaingan yang semakin kuat mengharuskan SDM meningkatkan kompetensi kinerja yang optimal dalam rangka menjaga kelangsungan hidup perusahaan.

Kinerja seorang karyawan merupakan hal yang bersifat individual, karena karyawan memiliki kemampuan yang berbeda-beda dalam mengerjakan tugasnya. Kinerja karyawan yang baik menentukan pencapaian produktifitas perusahaan/ pinstansi. Namun tidak semua karyawan memiliki kinerja yang bagus, masih pada karyawan yang memiliki kinerja yang tidak sesuai dengan harapan perusahaan/ instansi (Djuwarto, Istiatin \& Hartono 2017).

Setiap organisasi memiliki Budaya kerja tersendiri yang berfungsi sebagai pola dasar tentang nilai keyakinan yang menjadi pacuan dalam berfikir dan bertindak. Kekuatan daripada budaya kerja dengan kata lain ditaati dari nilai organisasi yang kemudian menjadi dasar dalam berfikir dan bertindak yang akan mempengaruhi kinerja karyawan yang meningkat (Suzanto \& Muhiban, 2013).

Menurut Surono, Paramitha \& Warso (2016) padanya faktor budaya kerja dalam perusahaan/ instansi mempunyai dampak terhadap prestasi kerja untuk meningkatkan produktivitas karyawan dalam menjalankan misi perusahaan/ instansi lingkungan usaha yang memiliki peran sehingga dapat berkembang dengan meningkatkan nilai 
konsep dalam perusahaan/ instansi.

Budaya kerja berguna untuk meningkatkan kinerja karyawan. Tetapi tindakan yang dilakukan telah menggambarkan suatu kemampuan dan budaya kerja yang sebenarnya. Hal ini dapat ditentukan dalam menentukan cara dan indikator yang digunakan. Suatu penilaian yang menggunakan cara dan indikator sangat terbatas akan memberikan hasil yang kurang menggambarkan keadaan yang sebenarnya (Indraputra \& Sutrisna, 2013).

Faktor lain yang dapat meningkatkan kinerja karyawan merupakan kedisiplinan. Menurut Isvandiari \& Fuadah (2017) menyatakan kedisiplinan tidak bisa ditegakkan bila peraturan dibuat hanya berdasarkan instruksi lisan yang dapat berubah sesuai kondisi dan situasi. Dengan adanya aturan tertulis yang jelas, para karyawan akan mendapatkan kepastian mengenai pedoman yang boleh dilakukan dan tidak boleh dilakukan. Sehingga akan menghindarkan diri dari perilaku yang tidak sesuai dengan peraturan tersebut. Adanya masalah disiplin kerja yang umum ditimbulkan oleh karyawan dengan tingkat absensi yang tinggi, hal ini menunjukkan bahwa tingkat kedisiplinan karyawan masih rendah. Oleh karena itu kedisiplinan dalam suatu organisasi harus ditegakkan, karena tanpa dukungan kedisiplinan karyawan yang baik maka sulit untuk mewujudkan tujuan dari organisasi tersebut (Nugroho, 2013).

Selain kedisiplinan kinerja juga dipengaruhi oleh insentif merupakan salah satu jenis penghargaan yang dikaitkan dengan penilaian kinerja pegawai. Semakin tinggi kinerja pegawai, semakin besar pula insentif yang diberikan oleh perusahaan/ instansi. Pemberian insentif dilakukan untuk meningkatkan kinerja pegawai terhadap output yang dihasilkan (Djuwarto, Istiatin \& Hartono, 2017).

Dari uraian diatas peneliti layak untuk penelitian dengan judul Budaya Kerja, Kedisiplinan, dan Insentif Terhadap Kinerja Karyawan Universitas Tunas Pembangunan (UTP) Surakarta.

\section{METODE PENELITIAN}

Penelitian ini menggunakan data primer yang diperoleh dari karyawan Universitas Tunas Pembangunan (UTP) Surakarta. Teknik pengambilan sampel yang digunakan adalah sampel sensus kepada 63 karyawan sebagai responden. Metode analisis data yang digunakan antara plain : uji instrument (validitas dan reliabilitas ) dan uji hipotesis (analisis regresi linier berganda, uji t , uji F, dan koefisien determinasi (R2). Hipotesis dalam penelitian ini adalah :

1) Diduga budaya kerja, kedisiplinan, dan insentif berpengaruh simultan dan signifikan terhadap kinerja karyawan pada Universitas Tunas Pembangunan (UTP) Surakarta.

2) Diduga budaya kerja berpengaruh positif dan signifikan terhadap kinerja karyawan pada Universitas Tunas Pembangunan (UTP) Surakarta.

3) Diduga kedisiplinan berpengaruh positif dan signifikan terhadap kinerja karyawan pada Universitas Tunas Pembangunan (UTP) Surakarta. 
4) Diduga insentif berpengaruh positif dan signifikan terhadap kinerja karyawan pada Universitas Tunas Pembangunan (UTP) Surakarta.

\section{HASIL DAN PEMBAHASAN}

Hasil analisis deskriptif menunjukan bahwa responden berjenis kelamin laki-laki (77\%) dan perempuan (23\%). Semua data dari penyebaran kuisioner telah lolos uji instrument. Hasil uji asumsi klasik:

1) Uji Normalitas

Berdasarkan hasil perhitungan uji Kolmogorov Smirnov dapat diketahui bahwa $\mathrm{p}$-value adalah 0,430. Nilai p-value ternyata lebih besar dari $\alpha(\mathrm{p}>0,05)$, maka dapat disimpulkan sebaran datanya normal.

2) Uji Multikolineritas

Tabel 1. Hasil Uji Multikolineritas

\begin{tabular}{|l|c|c|}
\hline \multicolumn{1}{|c|}{ Variabel } & Toleransi & VIF \\
\hline Budaya Kerja & 0,415 & 2,409 \\
\hline Kedisiplinan & 0,565 & 1,771 \\
\hline Insentif & 0,510 & 1,960 \\
\hline
\end{tabular}

Berdasarkan tabel diatas dapat disimpulkan bahwa model regresi tersebut tidak terjadi multikolineritas karena nilai $\mathrm{VIF}<10$ dan Toleransi $>0,1$.

3) Uji Hesteroskedastisitas

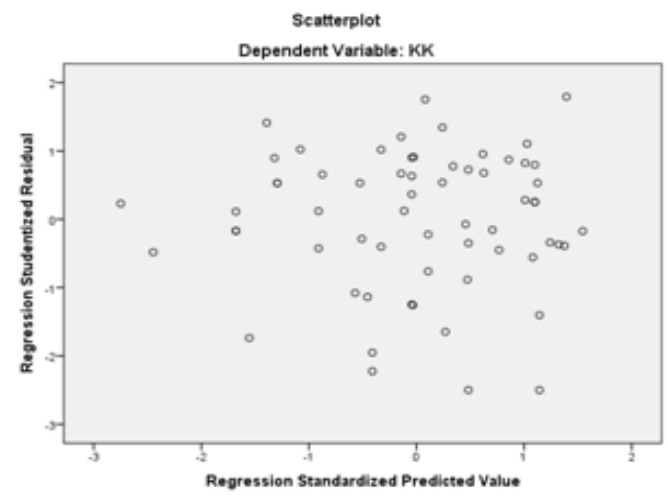

Gambar 1. Hasil Uji Hesteroskedastisitas

Berdasarkan tabel diatas menunjukan bahwa titik-titik tersebut berada diatas dan dibawah nilai 0 . Hasil tersebut menunjukkan bahwa tidak terjadi adanya heteroskedastisitas.

Untuk pengujian uji $\mathrm{f}$ diperoleh hasil bahwa nilai $\mathrm{F}_{\text {hitung }}(3,282)>\mathrm{F}_{\text {tabel }}(2,76)$ dengan probabilitas sebesar $0,000(\mathrm{p}<0,05)$. Hal ini menunjukkan $\mathrm{F}$ hitung berada pada 
daerah Ho ditolak artinya terdapat pengaruh yang signifikan dari budaya kerja, kedisiplinan, dan insentif secara simultan terhadap kinerja karyawan. Model persamaan regresi disusun sebagai berikut :

$$
\mathrm{Y}=5,051-0,004 \cdot X_{1}+0,256 . X_{2}+0,200 . X_{3}
$$

Dari hasil uji $\mathrm{t}$ diperoleh hasil budaya kerja berpengaruh positif dan simultan terhadap kinerja karyawan. Hal ini terbukti dari nilai $t_{\text {hitung }}(3,651)<t_{\text {tabel }}(2,001)$ dengan nilai signifikansi $<\alpha(0,05)$. Kedisiplinan berpengaruh positif pdan signifikan terhadap kinerja karyawan. Hal ini terbukti dari nilai $t_{\text {hitung }}(2,990)>t_{\text {tabel }}(2,001)$ dengan nilai signifikansi $<\alpha(0,05)$. Demikian juga insentif berpengaruh positif dan signifikan terhadap kinerja karyawan. Hal ini terbukti dari nilai $\mathrm{t}$ hitung $(3,374)>\mathrm{t}$ tabel $(2,004)$ dengan nilai signifikansi $<\alpha(0,05)$. Hasil analisis dalam penelitian ini menunjukkan $R^{2}$ sebesar 0,528 $(52,8 \%)$. Hal ini berarti budaya kerja, kedisiplinan dan insentif mampu berkontribusi sebesar 52,8\% terhadap kinerja karyawan. Sedangkan sisanya sebesar 47,2\% dipengaruhi oleh variabel lain diluar penelitian misalnya motivasi, stress kerja, kepemimpinan, punisment dan lain sebagainya.

\section{KESIMPULAN}

Dari pembahasan dan hasil diatas, dapat ditarik beberapa kesimpulan:

1) Budaya kerja, kesiplinan dan Insentif secara simultan berpengaruh positif dan signifikan terhadap Kinerja Karyawan Universitas Tunas Pembangunan (UTP) Surakarta.

2) Budaya kerja berpengaruh positif dan signifikan terhadap Kinerja Karyawan Universitas Tunas Pembangunan (UTP) Surakarta.

3) Kedisiplinan berpengaruh positif dan signifikan terhadap Kinerja Karyawan Universitas Tunas Pembangunan (UTP) Surakarta.

4) Insentif berpengaruh positif dan signifikan terhadap Kinerja Karyawan Universitas Tunas (UTP) Surakarta.

\section{DAFTAR PUSTAKA}

Amir, Mohammad Faisal, 2015. Memahami Evaluasi Kinerja Karyawan,Konsep, dan Penilaian Kinerja di Perusahaan. Jakarta: Penerbit Mitra Wacana Media.

A.A. Anwar Prabu Mangkunegara. 2015. Manajemen Sumber Daya Manusia Perusahaan, Bandung : Remaja Rosdakarya.

Arianto, Dwi Agung Nugroho. 2013. Pengaruh Kedisiplinan, Lingkungan Kerja dan Budaya Kerja terhadap Kinerja Tenaga Pengajar ( Studi Pada Yayasan Pendidikan Luar Biasa Kabupaten Demak). Jurnal Economia, Vol 9 No 2 Hal 191-200.

Bachrun, Saifuddin. 2011. Menghitung Tunjangan, Insentif, Bonus dan Fasilitas dalam Praktik. Jakarta: Penerbit PP Mnajemen. 
Djuwarto.,et.al. 2017. Pengaruh Insentif, Kompetensi, dan Lingkungan Kerja Terhadap Kinerja Pegawai Dinas Pekerjaan Umum Kabupaten Sukoharjo. Jurnal Akuntansi dan Pajak, Vol. 18, No. 01, Juli 2017.

Hasibuan, Malayu S.P, 2011. Manajemen Sumber Daya Manusia. Jakarta: PT Bumi Askara.

Indraputra, T., \& Sutrisna, E. (2013). Disiplin, Motivasi, Budaya Kerja dan Kinerja. Jurnal Administrasi Pembangunan, Volume 1 Nomor 3 Juli 2013, 219-323.

Robbins, Stephen P., 2006. Perilaku Organisasi PT Indeks. Jakarta: Kelompok Gramedia

Sarwoto. 2010. Dasar-dasar Organisasi dan Manajemen, Cetakan keenambelas. Jakarta: Ghalia Indonesia

Surono, et al. 2016. Pengaruh Gaya Kepemimpinan Transformasional, Budaya Organisasi dan Disiplin Kerja Terhadap Produktivitas Kerja dengan Etos Kerja sebagai Variabel Intervening pada PT. Muliapack Gravurindo Semarang. Journal of Management Vol. 02 No. 02 Maret 2016

Suzanto, B, Muhiban A., 2013. Pengaruh Budaya Organisasional, Disiplin Kerja, dan Motivasi Kerja Terhadap Kinerja Aparat Kecamatan Batujajar Kabupaten Bandung. Jurnal Ekonomi, Bisnis \& Entrepreneurship Vo. 7, No. 1, April 2013, 20 - 29 ISSN 2443-0633

Taliziduhu, N. 2013. Teori Budaya Organisasi. Jakarta: Cetakan Kedua, PT. Rineka Cipta 